\title{
A construção da sexologia como profissão em Portugal: composição de um grupo profissional e tipos de sexólogos
}

\author{
The construction of sexology as a profession in Portugal: \\ composition professional group and types of sexologists
}

Violeta Alarcão ${ }^{1}$

Fernando Luís Machado ${ }^{2}$ Alain Giami ${ }^{3}$
${ }^{1}$ Instituto de Medicina Preventiva e Saúde Pública, Faculdade de Medicina, Universidade de Lisboa. Av. Professor Egas Moniz, s/n. 1649-028 Lisboa Estremadura Portugal. violeta.alarcao@gmail.com

${ }^{2}$ Centro de Investigação e Estudos de Sociologia, Instituto Universitário de Lisboa. Lisboa Portugal. ${ }^{3}$ Institut de la Santé et de la Recherche Médicale. Paris França.

\begin{abstract}
This study sets out to discuss the emergence of the profession of sexologist in Portugal, comparing its development with international trends. This research also seeks to understand the self-identification of sexologists and the significances they attribute to it. The empirical information presented derives from a survey conducted with 91 Portuguese sexologists identified through the leading professional associations and from 44 in-depth interviews with experts selected by intentional sampling to ensure the diversity of Portuguese sexologists. The results of the survey indicate that the Portuguese sexologist is on average 43 years old, mainly female, non-physician, and has training in sexology. Considering the qualifications of the interviewees, their professional trajectories and the activities they develop in the field, and the discourses related to their ideals of the profession, a typology was found with five types: sexologists by vocation, sexologist by clinical practice, sexologists by certification, social scientist-sexologists and sexologists by media coverage. The survey identified an interesting diversity of practices and professional conceptions in the field of sexology in Portugal. Being a sexologist appears to be more associated with the ideals of the profession than the time devoted to same.
\end{abstract}

Key words Sexology, Sexologist, Professions, Portugal
Resumo Este estudo visa discutir a emergência da profissão de sexólogo em Portugal, comparando a sua evolução com as tendências internacionais. Procura igualmente compreender as autoidentificações profissionais dos sexólogos e os sentidos que eles thes atribuem. A informação empírica apresentada resulta de um inquérito por questionário a 91 sexólogos identificados através das principais associações profissionais e de 44 entrevistas aprofundadas junto de peritos selecionados através de uma amostragem intencional para assegurar a diversidade dos sexólogos portugueses. Os resultados do inquérito indicam que em média o sexólogo português tem 43 anos, é maioritariamente do sexo feminino, não médico, e tem formação em sexologia. Considerando as habilitações, os percursos profissionais e as atividades desenvolvidas no campo, e os discursos dos entrevistados relativos aos seus ideais de profissão, obtivemos uma tipologia com cinco categorias: sexólogos por vocação, sexólogos pela prática clínica, sexólogos por certificação, sexólogos-cientistas sociais e sexólogos por mediatização. A pesquisa identificou uma interessante diversidade de práticas e conceções profissionais no campo da sexologia portuguesa. Ser sexólogo parece estar mais ligado aos ideais sobre a profissão do que ao tempo dedicado à mesma.

Palavras-chave Sexologia, Sexólogo, Profissões, Portugal 


\section{Introdução}

A sexologia emergiu na segunda metade do século XIX e constituiu-se como uma scientia sexualis pluridisciplinar, englobando várias áreas do saber, médicas e não médicas, bem como um leque variado de práticas terapêuticas, de formação, e de intervenção ${ }^{1}$. A constituição da sexologia enquanto área do saber tem sido estudada com um enfoque histórico e sociológico desde a obra pioneira de Foucault ${ }^{2}$, passando pelos trabalhos de Béjin ${ }^{3,4}$, Irvine ${ }^{5}$ e Weeks $s^{6}$, aos balanços mais atuais de Giami ${ }^{1}$ e Russo ${ }^{7}$. Também a sexologia enquanto profissão tem sido objeto de pesquisas, nomeadamente, na Europa ${ }^{8,9}$, no Canada $^{10} \mathrm{e}$ na América Latina ${ }^{11}$. Nalguns países, alguns dos mais influentes sexólogos têm igualmente procurado reconstituir a história da sexologia ${ }^{12-15}$.

Este artigo pioneiro quanto ao estudo de um grupo profissional visa a elaborar uma sociografia dos sexólogos em Portugal e compreender as autoidentificações destes com a sexologia a partir de uma estratégia metodológica mista, que articula dados resultantes de um inquérito com esses profissionais em Portugal e material recolhido através de entrevistas aprofundadas. Adicionalmente, procura discutir a emergência da profissão de sexólogo em Portugal, comparando a sua evolução com as tendências internacionais. Primeiramente é feita uma introdução ao surgimento da sexologia portuguesa, com um enfoque nos fatores de natureza social, cultural e institucional que têm impulsionado a sua profissionalização. De seguida, são detalhados os procedimentos metodológicos que orientaram a realização de uma sociografia da sexologia em Portugal e possibilitaram a análise dos diferentes modos de identificação desta no país, produzindo conhecimento sobre a diversidade dos sentidos atribuídos à identidade de sexólogo. Numa terceira parte, é apresentada a informação empírica resultante do inquérito por questionário a 91 sexólogos portugueses e das 44 entrevistas semidiretivas junto de atores-chave da sexologia. Por fim, discute-se a pertinência social, real e simbólica da emergência da profissão de sexólogo em Portugal e algumas implicações que decorrem desta evolução profissional para o papel da sexologia enquanto ciência e profissão.

\section{A sexologia enquanto profissão em Portugal}

Em Portugal, foi a partir dos anos 70 que a queda do regime da ditadura e a construção de um regime democrático com novas condições económicas, políticas e sociais possibilitaram o crescimento das profissões ${ }^{16}$. Mas foi só a partir da década de noventa que vários grupos profissionais passaram a ser alvo de estudos socioló$\operatorname{gicos}^{17,18}$.

Os membros das diferentes profissões apresentam características e especificidades múltiplas, histórica e geograficamente variáveis, ocupam posições hierárquicas diversas, e obtêm níveis diferenciados de prestígio, poder, competência e autoridade ${ }^{19}$. Essa heterogeneidade tem estado presente desde a origem da sexologia portuguesa. Não existe um caminho claro e definido para se tornar um sexólogo em Portugal. Não existe tampouco um consenso quanto à definição de um sexólogo, ou uma enunciação das suas competências e uma descrição exata das suas tarefas. Esta situação é semelhante a de outros países europeus ${ }^{8}$.

Os trabalhos do médico neurologista Egas Moniz, com uma tese de doutoramento, em 1901, intitulada "A Vida Sexual - Fisiologia", seguida em 1902 de "A Vida Sexual - Patologia", fazem com que possa ser considerado o precursor português da sexologia ${ }^{20}$. Neste seu trabalho antecipador, e no enquadramento da racionalidade biológico/científica da época, designada por Béjin ${ }^{3}$ de "protossexologia", em que o discurso médico se contrapunha ao legal ou religioso, a sexualidade passou do domínio das perversões morais para o das disfunções sexuais. Porém, somente no final dos anos sessenta, e especialmente após a revolução de abril de 1974, com a restauração da democracia, é que se pode falar da emergência da sexologia em Portugal, com o surgimento das consultas nos hospitais públicos de Coimbra, Lisboa e Porto. Este aspeto é comparável à realidade da América Latina, onde o processo de constituição da sexologia na Argentina, Brasil e Chile foi também marcado pela ascensão e queda dos respetivos regimes militares ditatoriais ${ }^{11}$.

Em Portugal, a terapia sexual foi desenvolvida por um grupo pioneiro de psiquiatras, Afonso de Albuquerque, Allen Gomes, Pacheco Palha e Silveira Nunes, com percursos pessoais e profissionais semelhantes, e interessados em implementar no país o trabalho desenvolvido nos Estados Unidos da América por Masters e Johnson ${ }^{21}$. A Sociedade Portuguesa de Andrologia (SPA) foi fundada em 1979, com um enfoque exclusivamente na saúde sexual masculina e na infertilidade, mas constituída com 29 médicos de várias especialidades $^{22}$. O incremento e o interesse pela andrologia nos últimos anos conduziram progressivamente à admissão de novos membros, es- 
pecialmente da área da urologia. A criação da Sociedade Portuguesa de Sexologia Clínica (SPSC) foi oficializada em 1985, com 116 profissionais. Apesar da colaboração entre os profissionais de ambas as sociedades científicas, o campo da sexologia e terapia sexual foi sendo mais associado à SPSC. A medicalização das questões de sexualidade e o surgimento de tratamentos médicos eficazes mudaram em parte esta situação, e o número de profissionais de saúde no campo de sexologia aumentou ${ }^{23}$. A formação em sexologia foi implementada por ambas as sociedades, juntamente com a Universidade Lusófona (desde 1998) e outras instituições. A SPSC fornece um título de terapeuta sexual para aqueles que realizem os seus dois anos do programa de formação, que inclui sessões de supervisões, pesquisa e prática clínica ${ }^{24}$. Outras instituições emitem títulos de mestrado e cursos pós-graduados.

A Associação para o Planeamento da Família (APF) foi criada em 1967, ainda durante o regime ditatorial. Além de pioneira na promoção do planeamento familiar em Portugal, a APF teve um papel chave na criação de serviços para jovens, na formação de profissionais e na educação sexual nas escolas ${ }^{25}$.

No cruzamento dos campos político e da sexualidade, deve destacar-se o efeito que teve o aparecimento do Vírus de Imunodeficiência Humana (HIV) e da Síndrome de Imunodeficiência Adquirida (AIDS). Em Portugal, o primeiro caso clínico de infeção pelo HIV foi diagnosticado em Outubro de 1983. Se, numa primeira fase, a emergência do HIV/AIDS abalou o equilíbrio de forças conseguido em duas décadas de liberalização dos costumes, atitudes e comportamentos sexuais, o pânico moral face a uma nova e desconhecida doença deu lugar a uma prioritização na gestão pública do problema ${ }^{26}$. Neste contexto, o Ministério da Saúde criou, em 1985, o Grupo de Trabalho da AIDS, e inicia-se em Portugal uma vasta pesquisa às atitudes e aos comportamentos sexuais das populações ${ }^{27-31}$, seguindo o exemplo de outros países ${ }^{32-34}$. Emergem também neste quadro alguns movimentos sociais de combate à estigmatização da doença e discriminação das pessoas seropositivas, como resposta a um discurso do risco associado à sexualidade, uma argumentação também moralista e moralizadora, em torno da associação entre comportamentos desviantes e o HIV/AIDS.

\section{Métodos}

Para dar resposta aos objetivos de elaboração de uma sociografia dos sexólogos em Portugal e de compreensão das autoidentificações destes com a sexologia foi delineada uma estratégia metodológica mista. A informação apresentada resulta de material recolhido através de entrevistas semidiretivas com atores-chave da sexologia em Portugal e dos dados resultantes de um inquérito por questionário enviado por correio a todos os profissionais da sexologia identificados.

A pesquisa seguiu a metodologia do estudo Euro-Sexo, o primeiro mapeamento dos profissionais de sexologia realizado em França ${ }^{9}$, e duplicado posteriormente em seis países europeus. A versão original em francês do questionário contemplava 85 perguntas organizadas nas seguintes seções: 1) Formação profissional inicial; 2) Formação em sexologia; 3) Prática profissional; 4) Prática clínica em sexologia; 5) Relação com os clientes; 6) Opiniões sobre sexologia; 7) Outras atividades no campo da sexologia; e 8) Informações sociodemográficas. Foi traduzido para o português, comparado com a versão brasileira traduzida pelo Centro Latino-Americano em Sexualidade e Direitos Humanos ${ }^{11}$ e adaptado ao contexto português.

O presente artigo tem como foco a realização de uma sociografia da sexologia em Portugal, resultante da necessidade de saber quem são os protagonistas deste campo em termos de perfil social e profissional. Representa também uma primeira tentativa de mapear as diferenças em termos de género e categoria profissional (categorias médicas vs. não médicas) e de as relacionar com as posições ocupadas no campo. A "base de dados de sexólogos" foi obtida a partir de listas públicas e das fornecidas pelas principais associações profissionais: a SPSC forneceu as listas de todos os membros associados, dos detentores do título de Terapeuta Sexual, e dos antigos alunos do Curso de Pós-Graduação em Sexologia Clínica; a SPA forneceu a lista dos seus associados; e a APF disponibilizou a lista dos profissionais dos seus projetos a nível nacional. A juntar a essa informação foi obtida a lista de atuais e antigos alunos do Mestrado Transdisciplinar de Sexologia da Universidade Lusófona e realizada pesquisa no anuário telefónico das páginas amarelas com as entidades "sexólogo" e "terapeuta sexual". A "base de dados de sexólogos" engloba, por isso, tanto as pessoas que fazem parte de associações e se beneficiam de um reconhecimento da sua atividade profissional, como os indivíduos que 
se apresentam publicamente como "sexólogos", independentemente das suas qualificações académicas ou reconhecimento profissional.

Um total de 490 indivíduos foi identificado como potenciais sexólogos. Após o primeiro contato, 28 foram excluídos: 23 por estarem incontatáveis, 4 por se terem considerado não elegíveis e 1 por ter falecido.

O inquérito por questionário realizou-se entre agosto de 2012 a janeiro de 2013. O número total de indivíduos que devolveram o questionário preenchido foi 91 (20\% de todos os participantes elegíveis). As taxas de participação variaram por afiliação: de $12 \%$ da SPA (20 de 164) para $90 \%$ da APF ( 19 de 21 ) e $30 \%$ da SPSC ( 25 de 84); e género: as mulheres (58 de 221, 26\%) foram mais participativas do que os homens ( 33 de $241,14 \%)$.

Para compreender e interpretar os diferentes modos de identificação da sexologia em Portugal, produzindo conhecimento sobre a diversidade dos sentidos atribuídos à identidade de sexólogo, realizou-se um estudo qualitativo baseado na coleta de dados através de entrevistas semidiretivas $a$ atores-chave da sexologia. A seleção dos participantes seguiu uma estratégia de amostragem intencional para garantir a constituição de um grupo socialmente significativo e heterogéneo quanto às variáveis-chave na estruturação do campo e às tensões que atravessam a rede de profissionais, nomeadamente as relações de género e as de poder entre médicos e não médicos.

Primeiramente, foi feito um levantamento de sítios institucionais ou pessoais na Internet usando o motor de busca Google, que resultou num conjunto heterogéneo de atores, formado por sociedades científicas, Organizações Não Governamentais (ONG), clínicas, núcleos em universidades, e profissionais ligados à sexologia, através do qual foi possível identificar os atores principais do campo.

Os critérios de seleção incluíram: (a) ser membro-fundador, ex-presidente, ou participante ativo de uma instituição relacionada com a sexologia; (b) ser um especialista da sexualidade com um papel no campo da sexologia; (c) ser considerado pelos atores-chave um ator relevante no campo da sexologia; e (d) aceitar e estar disponível para ser entrevistado. Os cientistas sociais foram incluídos para ampliar nossa visão sobre o papel profissional da sexologia e selecionados a partir de investigadores da sexualidade com interações com reconhecidos sexólogos.

A partir de uma lista final de 55 profissionais, obtiveram-se 44 entrevistas: 22 médicos,
13 psicólogos e 9 cientistas sociais. As entrevistas realizaram-se entre novembro de 2011 e abril de 2012, tiveram entre 45 minutos e 2 horas de duração, e foram gravadas com o consentimento dos participantes. A análise das entrevistas seguiu a perspetiva da sociologia das profissões, procurando identificar e interpretar a diversidade de níveis de prestígio, poder, competência e autoridade na profissão de sexólogo ${ }^{19}$. Considerando as diferentes habilitações de base e as competências adquiridas pelos entrevistados, a sua antiguidade no campo e os seus múltiplos percursos profissionais e atividades desenvolvidas no campo, e também os discursos relativos aos seus ideais de profissão, foi construída uma tipologia de sexólogos portugueses. Os ideais-tipos devem ser encarados enquanto construções teóricas e metodológicas que acentuam determinados traços típicos para efeitos de interpretação, e constituem uma aproximação à diversidade dos sexólogos a partir dos casos analisados. Apesar dos sexólogos entrevistados poderem partilhar características de mais de um tipo, manteve-se, para fins heurísticos, a alocação num único ideal-tipo.

\section{Resultados}

\section{Uma sociografia dos sexólogos}

Os 91 sexólogos que responderam ao inquérito por questionário tinham uma idade média de 43,07 anos ( \pm 12.82 ): $44,4 \%$ (40) tinham 25 39 anos de idade, $33,0 \%$ (30) estavam na faixa etária dos 40-54 anos, e 19,0\% (21) tinham 55 e mais anos. Enquanto a grande maioria dos membros do grupo mais velho é constituída por médicos $(16,84,2 \%)$, a do grupo mais jovem é formada por não médicos $(36,90 \%)$. O número de homens é maior nos grupos etários mais velhos e menor nos mais jovens. Do ponto de vista geográfico, as zonas de maior índice de urbanização (Lisboa, Região Norte) concentram a maioria dos sexólogos.

Embora sejam maioritários no grupo mais velho, os indivíduos com a profissão de médico são minoritários no conjunto da amostra $(38,5 \%)$, sendo que a maioria destes médicos são homens $(24,26,4 \% ; \mathrm{p}<0,001)$. Pelo contrário, as mulheres são maioritárias entre os sexólogos com outras profissões $(47,51,6 \%)$, constituindo as psicólogas o maior grupo $(37,40,7 \%)$. A distribuição dos sexólogos de acordo com o género e profissão encontra-se resumida na Tabela 1. 


\begin{tabular}{|c|c|c|c|c|c|c|}
\hline & \multicolumn{3}{|c|}{ Idade $(\mathbf{n}=\mathbf{8 9})$} & \multicolumn{2}{|c|}{ Género (n = 91) } & \multirow[b]{2}{*}{$\begin{array}{c}\text { Total }(\mathbf{n}=91) \\
(\mathbf{n}, \%)\end{array}$} \\
\hline & $\begin{array}{l}25-39 \\
(n, \%)\end{array}$ & $\begin{array}{l}40-55 \\
(n, \%)\end{array}$ & $\begin{array}{c}55+ \\
(n, \%)\end{array}$ & $\begin{array}{l}\text { Homens } \\
(\mathbf{n}, \%)\end{array}$ & $\begin{array}{c}\text { Mulheres } \\
(\mathbf{n}, \%)\end{array}$ & \\
\hline Médicos & $4(4,5)$ & $14(15,7)$ & $16(18,0)$ & $24(26,4)$ & $11(12,1)$ & $35(38,5)$ \\
\hline Urologistas & $4(4,5)$ & $5(5,6)$ & $6(6,7)$ & $14(15,4)$ & $1(1,1)$ & $15(16,5)$ \\
\hline Ginecologistas & 0 & $4(4,5)$ & $2(2,2)$ & $2(2,2)$ & $5(5,5)$ & $7(7,7)$ \\
\hline Psiquiatras & 0 & $1(1,1)$ & $4(4,5)$ & $2(2,2)$ & $3(3,3)$ & $5(5,5)$ \\
\hline Endocrinologistas & 0 & $1(1,1)$ & $3(3,4)$ & $4(4,4)$ & $0(0,0)$ & $4(4,4)$ \\
\hline Outros & 0 & $3(3,4)$ & $1(1,1)$ & $2(2,2)$ & $2(2,2)$ & $4(4,4)$ \\
\hline Outras profissões & $36(40,4)$ & $16(18,0)$ & $3(3,4)$ & $9(9,9)$ & $47(51,6)$ & $56(61,5)$ \\
\hline Psicólogo & $29(32,6)$ & $10(11,2)$ & $2(2,2)$ & $3(3,3)$ & $37(40,7)$ & $40(44,0)$ \\
\hline Enfermeiro & $4(4,5)$ & $2(2,2)$ & 0 & $3(3,3)$ & $4(4,4)$ & $7(7,7)$ \\
\hline Outras & $3(3,4)$ & $5(5,6)$ & $1(1,1)$ & $3(3,3)$ & $6(6,5)$ & $9(9,9)$ \\
\hline Total & $40(44,9)$ & $30(33,7)$ & $19(21,3)$ & $33(36,3)$ & $58(63,7)$ & $91(100)$ \\
\hline
\end{tabular}

Valores $\mathrm{p}<0,05$ a negrito.

Em termos de formação académica, cerca de 14\% (13) dos participantes eram doutorados; 17\% (15) tinham um mestrado; 6\% (5) uma pós-graduação; 63\% (57) uma licenciatura; e 1\% (1) um bacharelato. Se a maioria dos inquiridos referiram ter alguma formação específica em sexologia ou sexualidade humana $(68,74,7 \%)$, quase todos dizem também que se beneficiariam em aprofundar os conhecimentos em sexologia (88, 96,7\%). Mais de metade dos sexólogos inquiridos tinha uma pós-graduação em sexologia $(54,59,3 \%)$, sendo as mulheres $(39,67.2 \%)$ e o grupo de não médicos $(36,64,3 \%)$ os que mais reportaram essa formação.

A larga maioria dos inquiridos exerce algum tipo de prática clínica $(66,72,5 \%)$, bem como atividades ligadas ao ensino/formação (51, 56,0\%); vários são os que desenvolvem atividades dirigidas à comunidade $(41,45,1 \%)$, e menos os que afirmaram fazer investigação $(36,39,6 \%)$.

Os sexólogos não médicos dedicam significativamente mais tempo profissional à sexologia $(\mathrm{p}=0,006)$. As mulheres também dedicam mais tempo à sexologia do que os homens, mas sem diferenças estatisticamente significativas.

Perante a pergunta sobre a sua identidade profissional, apresentada na Tabela 2, os participantes não médicos referiram significativamente mais considerar-se como educadores sexuais, enquanto os médicos, para além de indicarem as categorias de sexólogo e terapeuta sexual, indicaram outra categoria (andrologista, por exemplo). Os homens também se consideram significativamente mais do que as mulheres como pertencen- do a outra categoria e menos como educadores sexuais.

\section{Uma tipologia da profissão de sexólogo}

Dos 44 entrevistados no estudo qualitativo, 26 eram homens e 22 médicos. Dos 22 médicos, 6 eram psiquiatras, 6 endocrinologistas, 4 urologistas, 4 ginecologistas e 2 generalistas. No que diz respeito às atividades desenvolvidas no campo da sexologia, 33 faziam clínica, a maior parte em articulação com a investigação e o ensino ou com atividades ligadas à mídia. Em termos da região principal para o exercício da atividade, 33 o faziam em Lisboa, 5 no Porto, 3 em Coimbra, 2 em Aveiro e 1 no Algarve.

Uma tipologia explicativa foi desenvolvida para capturar a diversidade dos sexólogos portugueses, compreender as suas autoidentificações profissionais e os sentidos que atribuem a estas. A tipologia foi construída semi-indutivamente a partir das entrevistas, e permitiu identificar cinco categorias de sexólogos: por vocação, pela prática clínica, por certificação, como cientistas sociais e por mediatização (Tabela 3).

Enquanto os discursos baseados na ideologia da vocação centram-se na dimensão moral e na legitimação pelas características e percursos pessoais, os discursos da ideologia profissional dos sexólogos pela prática clínica centram-se na dimensão clínica e na legitimação pela capacidade de intervenção nesse nível. Os discursos dos sexólogos por certificação são discursos da ideologia da scientia sexualis pluridisciplinar e baseiam-se 
Tabela 2. Atualmente, considera-se... (escolha múltipla).

\begin{tabular}{lrrrrr}
\hline & $\begin{array}{c}\text { Médicos } \\
(\mathbf{n}, \mathbf{\%})\end{array}$ & $\begin{array}{c}\text { Não-médicos } \\
(\mathbf{n}, \mathbf{\%})\end{array}$ & $\begin{array}{c}\text { Homens } \\
(\mathbf{n}, \mathbf{\%})\end{array}$ & $\begin{array}{c}\text { Mulheres } \\
(\mathbf{n}, \mathbf{\%})\end{array}$ & $\begin{array}{c}\text { Total } \\
(\mathbf{n}, \mathbf{\%})\end{array}$ \\
\hline Sexólogo/Sexologista & $6(17,1)$ & $9(16,1)$ & $4(12,1)$ & $11(19,0 \%)$ & $15(16,5)$ \\
Terapeuta sexual & $2(5,7)$ & $9(16,1)$ & $\mathbf{0}(\mathbf{0 , 0})$ & $\mathbf{1 1}(\mathbf{1 9 , 0})$ & $11(12,1)$ \\
Ambos & $7(20,0)$ & $9(16,1)$ & $6(18,2)$ & $10(17,2)$ & $16(17,6)$ \\
Nenhum dos dois & $20(57,1)$ & $29(51,8)$ & $\mathbf{2 3 ( 6 9 , 7 )}$ & $\mathbf{2 6 ( 4 4 , 8 )}$ & $49(53,8)$ \\
Educador sexual & $\mathbf{3 ( 8 , 6 )}$ & $\mathbf{2 8}(\mathbf{5 0 , 0})$ & $8(24,2)$ & $23(39,7)$ & $31(34,1)$ \\
Outro (Andrologista, Psicólogo, Investigador, etc.) $)$ & $\mathbf{1 8 ( 5 1 , 4 )}$ & $\mathbf{1 6 ( 2 8 , 6 )}$ & $\mathbf{1 8 ( 5 4 , 5 )}$ & $\mathbf{1 6 ( 2 7 , 6 )}$ & $34(37,4)$ \\
Nenhum & $2(5,7)$ & $0(0,0)$ & $2(6,1)$ & $0(0,0)$ & $2(2,2)$
\end{tabular}

Valores $\mathrm{p}<0,05$ a negrito.

na legitimação pela aquisição de saberes e competências formalmente certificadas. Os discursos das ciências sociais são teórico-empíricos sobre a sexualidade, cruzando outras áreas fronteiriças de saber, nomeadamente a família e o género e, por fim, os discursos dos sexólogos por mediatização são discursos para o grande público e centram-se na componente de gestão de recursos sociais e da imagem pessoal.

\section{Os sexólogos por vocação}

Este tipo é composto na sua maioria por psiquiatras (4), mas conta também com urologistas (2) e endocrinologistas (2), todos eles homens e com idades compreendidas entre os 60-80 anos. Encontram-se neste tipo os pioneiros da sexologia, como se percebe pelo excerto de um dos psiquiatras fundadores deste campo em Portugal:

A partir de 1970 começam-se a gerar alguns movimentos de sexologia na Europa... e as pessoas que têm agora a minha idade organizaram excursões, em França e na Suiça etc., para ir aos Estados Unidos visitar os institutos de sexologia, nomeadamente a São Luís e São Francisco, que era onde estava a ser feita a investigação sexológica.

Os entrevistados deste tipo, embora não contestem a referenciação enquanto peritos da sexologia, não se apresentam como sexólogos, uma vez que consideram essa categorização redutora da atividade que desenvolvem no campo.

O chamamento para a sexologia do subgrupo dos médicos psiquiatras, em particular, surgiu das suas leituras das obras de Masters e Johnson, e posteriormente de Helen Kaplan: Em 1969 vejo uma livraria e vejo 'Les réactions sexuelles de Masters e Johnson'. Comecei a ler o livro e o impacto foi terrivel. Conceitos fundamentais da sexualidade.
A eles coube o papel de criar as consultas de sexologia, as associações profissionais, as revistas e os manuais da especialidade, e fizeram escola, despertando e formando as gerações seguintes.

Este grupo de fundadores ainda mantém, na maioria dos casos, uma atividade clínica e uma visibilidade pública em congressos, atividades de formação e também na mídia, desempenhando um papel chave na construção da identidade profissional, e sendo referidos de forma consensual por todos os outros especialistas como figuras centrais do campo.

Neste grupo de sexólogos por vocação, inserem-se igualmente dois endocrinologistas e dois urologistas que tiveram um papel decisivo no desenvolvimento científico e associativo da andrologia em Portugal. No seu discurso é percetível um conceito e uma vontade de fazer da sexologia uma ciência e prática multidisciplinar.

\section{Os sexólogos pela prática clínica}

Os indivíduos deste grupo têm elevadas competências clínicas associadas à formação altamente qualificada e são maioritariamente médicos (12 em 15), mais alguns psicólogos clínicos. São na sua maioria homens com idades compreendidas entre os 40-60 anos. Um dos médicos urologistas entrevistados associa mesmo a prática da sexologia à vertente clínica, não podendo haver, na sua opinião, uma sem a outra: Um sexólogo é alguém que dedica a sua atividade profissional à clínica. Há muito poucos em Portugal e mesmo noutros países. A duração das consultas de sexologia e andrologia demora muito tempo, o que demove muitos profissionais para a prática nesta área.

Estes sexólogos são conhecidos e procurados por essas competências específicas que desenvol- 
Tabela 3. Tipologia da profissão de sexólogo em Portugal a partir das entrevistas.

\begin{tabular}{|c|c|c|c|c|c|}
\hline Tipo & Género & Idade & $\begin{array}{l}\text { Região de } \\
\text { atividade }\end{array}$ & $\begin{array}{c}\text { Profissão de } \\
\text { origem }\end{array}$ & $\begin{array}{c}\text { Áreas de atuação } \\
\text { em sexologia }\end{array}$ \\
\hline Por vocação & M & $60-70^{*}$ & Porto & Urologista & Clínica \\
\hline Por vocação & M & $70-80^{*}$ & Lisboa & Psiquiatra & Clínica \\
\hline Por vocação & M & $70-80^{*}$ & Lisboa & Endocrinologista & Clínica, ensino e investigação \\
\hline Por vocação & M & $70-80^{*}$ & Porto & Psiquiatra & Clínica \\
\hline Por vocação & M & $60-70$ & Lisboa & Endocrinologista & Clínica e ensino \\
\hline Por vocação & M & $70-80^{*}$ & Coimbra & Psiquiatra & Clínica e ensino \\
\hline Por vocação & M & $70-80^{*}$ & Lisboa & Urologista & Clínica \\
\hline Por vocação & M & $60-70^{*}$ & Porto & Psiquiatra & Clínica e ensino \\
\hline Pela clínica & M & $50-60$ & Lisboa & Ginecologista & Clínica, ensino e investigação \\
\hline Pela clínica & M & $40-50$ & Lisboa & Endocrinologista & Clínica e ensino \\
\hline Pela clínica & $\mathrm{F}$ & $50-60$ & Coimbra & Psiquiatra & Clínica \\
\hline Pela clínica & $\mathrm{F}$ & $30-40$ & Lisboa & Psicólogo & Clínica e ensino \\
\hline Pela clínica & M & $50-60$ & Lisboa & Endocrinologista & Clínica e ensino \\
\hline Pela clínica & M & $40-50$ & Lisboa & Psicólogo & Clínica e ensino \\
\hline Pela clínica & M & $40-50$ & Lisboa & Endocrinologista & Clínica e ensino \\
\hline Pela clínica & $\mathrm{F}$ & $40-50$ & Lisboa & Ginecologista & Clínica e promoção da saúde \\
\hline Pela clínica & $\mathrm{F}$ & $40-50$ & Lisboa & Psicólogo & Clínica e ensino \\
\hline Pela clínica & $\mathrm{F}$ & $40-50$ & Lisboa & Ginecologista & Clínica e promoção da saúde \\
\hline Pela clínica & M & $50-60$ & Lisboa & Urologista & Clínica, ensino e investigação \\
\hline Pela clínica & M & $50-60$ & Lisboa & Médico & Clínica e ensino \\
\hline Pela clínica & M & $40-50$ & Porto & Urologista & Clínica, ensino e investigação \\
\hline Pela clínica & M & $60-70$ & Lisboa & Psiquiatra & Clínica, ensino e investigação \\
\hline Pela clínica & $\mathrm{F}$ & $30-40$ & Lisboa & Endocrinologista & Clínica e ensino \\
\hline Por creditação & $\mathrm{F}$ & $30-40$ & Lisboa & Psicólogo & Clínica, promoção da saúde e investigação \\
\hline Por creditação & $\mathrm{F}$ & $30-40$ & Lisboa & Psicólogo & Clínica, ensino e investigação \\
\hline Por creditação & $\mathrm{F}$ & $40-50$ & Porto & Psicólogo & Clínica e ensino \\
\hline Por creditação & $\mathrm{F}$ & $30-40$ & Lisboa & Psicólogo & Clínica, ensino e investigação \\
\hline Por creditação & M & $40-50$ & Aveiro & Psicólogo & Clínica, ensino e investigação \\
\hline Por creditação & $\mathrm{F}$ & $30-40$ & Aveiro & Psicólogo & Clínica, ensino e investigação \\
\hline Pelas Ciências Sociais & M & $50-60$ & Lisboa & Cientista Social & Ensino, investigação e promoção da saúde \\
\hline Pelas Ciências Sociais & M & $50-60$ & Lisboa & Cientista Social & Ensino e investigação \\
\hline Pelas Ciências Sociais & M & $60-70$ & Lisboa & Cientista Social & Ensino e investigação \\
\hline Pelas Ciências Sociais & $\mathrm{F}$ & $30-40$ & Coimbra & Cientista Social & Ensino, investigação e promoção da saúde \\
\hline Pelas Ciências Sociais & $\mathrm{F}$ & $30-40$ & Lisboa & Cientista Social & Investigação e mídia \\
\hline Pelas Ciências Sociais & $\mathrm{F}$ & $30-40$ & Lisboa & Cientista Social & Investigação e promoção da saúde \\
\hline Pelas Ciências Sociais & M & $50-60$ & Lisboa & Cientista Social & Ensino, investigação e promoção da saúde \\
\hline Pelas Ciências Sociais & M & $40-50$ & Lisboa & Cientista Social & Ensino e investigação \\
\hline Pelas Ciências Sociais & $\mathrm{F}$ & $30-40$ & Lisboa & Cientista Social & Ensino e investigação \\
\hline Por mediatização & $\mathrm{F}$ & $50-60$ & Lisboa & Ginecologista & Clínica e mídia \\
\hline Por mediatização & $\mathrm{F}$ & $40-50$ & Lisboa & Psicólogo & Clínica e mídia \\
\hline Por mediatização & M & $40-50$ & Lisboa & Psicólogo & Clínica e mídia \\
\hline Por mediatização & $\mathrm{F}$ & $30-40$ & Algarve & Psicólogo & Clínica e mídia \\
\hline Por mediatização & M & $30-40$ & Lisboa & Psicólogo & Ensino e mídia \\
\hline
\end{tabular}

vem associando a clínica à investigação. Além da formação, a experiência e a prática clínica são componentes fundamentais, como refere um médico ginecologista:

Fazia-me impressão as doentes, as clientes fazerem-me perguntas e eu não saber responder. Havia uma série de expressões sociais que eu desconhecia - 'oh soutor, eu faço arroz fingido' - ninguém nos ensina. Primeiro era autodidata, os relatórios Kinsey, Masters e Johnson, Kaplan e depois frequentei alguns cursos, umas semanas, um mês, em Genebra, Bruxelas, México. 
Apesar da componente clínica ser a que ocupa maior destaque na sua prática, a visão que estes especialistas têm da sexologia é abrangente, como nos diz um dos endocrinologistas deste grupo:

A sexologia envolve muitas mais coisas do que às vezes é um sexólogo. É obrigatória uma abordagem multidisciplinar e eu, embora não seja sexólogo, faço sexologia, como é evidente. E depois eu faço uma sexologia especial que é do homem, e temos as pessoas que tratam da mulher. Depois aqui temos psicólogos, psiquiatras, endocrinologistas, urologistas, ginecologistas... portanto, o campo é muito aberto e penso que não se deve reduzir só à sexologia.

\section{Os sexólogos por certificação}

A maior parte dos sexólogos deste tipo dedica-se a atividades de investigação, que acumulam muitas vezes com atividades de coordenação (nomeadamente de associações) e gestão de projetos e atividades de formação.

Este tipo corresponde aos indivíduos que estão na linha da frente das associações e do debate em torno da identidade profissional. São os sexólogos que representam atualmente a sexologia, tanto a nível nacional como internacional, que assumem as atividades de terapia sexual, formação, investigação e difusão científica. Esta nova sexologia, mais reflexiva, é representada por um grupo de psicólogos clínicos ${ }^{6}$, altamente qualificados, críticos e desafiadores dos limites do campo, inovadores em termos das atividades que desenvolvem dentro da clínica, da investigação e na formação. Sobre a sexologia e este grupo específico de sexólogos, diz um dos cientistas sociais:

A maioria gosta disso como uma flor... Ler uma história da sexualidade ou estudar um inquérito sociológico sobre os próprios sexólogos, uma certa curiosidade mais ou menos voyeurística, até para perceber quem é que lá está. E outros por interesse genuino, pensamento crítico e por terem uma reflexividade grande sobre aquilo que fazem. Como a gente tem a sorte em Portugal de ter algumas pessoas deste segundo tipo, são elas que estão interessadas em que haja participação das ciências sociais e humanas.

A definição de um sexólogo não é simples nem isenta de ambiguidade, como refere um dos psicólogos representantes deste tipo: É difícil definir um sexólogo: não se deve fechar numa caixa. Em relação ao terapeuta sexual já é possível estabelecer regras: ter formação em sexologia e na área das dificuldades sexuais, ter uma prática clínica [...]
O processo e os critérios para o reconhecimento profissional dentro do campo devem ser exigentes e rigorosos, como indica uma das psicólogas entrevistadas:

Sexologista é alguém que tem formação clinica e que fez uma especialização na área da sexualidade humana, uma formação teórica e prática com supervisão. Um sexologista teria idealmente formação em áreas do conhecimento como a medicina, a psicologia, a antropologia e a sociologia. Isto é um percurso de uma vida, adquire-se ao longo do percurso académico e clínico.

Estes sexólogos não negam o trabalho anterior realizado pelos seus precursores, antes baseiam-se nos pilares erguidos, e atuam muitas vezes em articulação com aqueles mais clínicos na construção das novas pontes da sexologia.

\section{Os sexólogos-cientistas sociais}

Este tipo integra um grupo de cientistas sociais (9) com trabalho desenvolvido na área da sexualidade, ou seja, os investigadores e teóricos da sexualidade em Portugal, que, apesar de não pertencerem diretamente ao campo da sexologia clínica, têm, ou tiveram, um papel ativo na sua construção. Uma parte destes cientistas sociais tem redes profissionais estabelecidas com alguns dos sexólogos mais reconhecidos; outros foram responsáveis pelo desenvolvimento de grandes investigações na área da sexualidade e são, sobretudo, uma referência no meio académico. Verifica-se certo equilíbrio de género ( 5 homens e 4 mulheres), mas uma diferenciação em termos etários: os cientistas sociais do sexo masculino são em média mais velhos (50-60 anos) comparativamente aos do sexo feminino (30-40 anos).

Nas palavras de uma destas cientistas sociais: [A sexualidade] é um tecido cheio de linhas e cruzamentos tremendos. Porque isso vai desde a antropologia à psicologia, passando pela história e a sociologia, a enfermagem, a medicina ... De facto, as abordagens sociais à sexualidade tendem a privilegiar a interdisciplinaridade e as pontes entre várias áreas do saber. A sexualidade foi surgindo juntamente com outras áreas já consolidadas do saber e foi-se constituindo enquanto emergente. O papel das ciências sociais no campo da sexologia fica bem presente no relato de um dos entrevistados:

Criar um campo de discussão em que as pessoas se tornam mais reflexivas sobre o que fazem às vezes é o suficiente para que algumas coisas melhorem na sua prática. Coisas como grandes processos de estigmatização, como com a orientação sexual, é 
fundamental que mude a perspetiva. Agora quem vai ter de mudar a perspetiva técnica, não é o cientista social, são os próprios sexólogos. [...] Acho que alguns têm-no feito.

\section{Os sexólogos por mediatização}

Neste grupo encontram-se médicos (1), mas sobretudo psicólogos (4). Os entrevistados deste tipo dedicam a maior parte do seu tempo profissional enquanto sexólogos a atividades na televisão, rádio, internet (blogues sobre sexualidade e intimidade), e publicações de livros, inclusive de autoajuda, e de artigos de opinião na imprensa generalista sobre sexualidade. Obtêm sobretudo um reconhecimento social, mais do que pelos pares, o que em alguns casos é inexistente, como transparece no discurso de uma sexóloga por certificação:

Nós temos por um lado, e isso é inegável, uma representação de alta qualidade, porque dignificam não só a sexologia como a área de onde eles vêm, porque são pessoas que de facto são emblemáticas, e por outro lado temos uma série de exemplos que não são de tanta qualidade e que são sempre retratados como vindos do mesmo... e não são!

Apesar de os sexólogos por mediatização terem também formação em sexologia, não é esse o critério de entrada no campo. São figuras mediáticas e têm geralmente uma imagem de marca que ajuda no desenvolvimento do seu trabalho e na abertura da sexologia ao grande público. Nas palavras de uma médica ginecologista: No princípio não me acontecia, não sei se foi por causa da divulgação que faço nos meus livros e na televisão, mas agora marcam consulta unicamente por terem disfunções ou pequenos problemas sexuais. Chegam a ir homens sozinhos e vão perguntar sobre as mulheres.

\section{Discussão}

Este artigo visou traçar uma sociografia dos sexólogos em Portugal e, muito em particular, compreender, através de uma tipologia, as suas autoidentificações profissionais e os sentidos que atribuem a estas. Os dados do inquérito e das entrevistas mostram que o campo da sexologia em Portugal, tal como nos outros países ${ }^{11}$, não se limita à prática da terapia, e inclui os discursos médicos e também sociais da sexualidade, a organização social da profissão de sexólogo, pelas associações e pela variedade de formações, a organização de seminários e congressos a nível nacional e internacional, as diferentes práticas e ideologias. Outra dimensão do campo, desde a sua origem, prende-se com a intervenção social e o ativismo político, a educação sexual e a promoção da saúde, nomeadamente ao nível da prevenção do HIV/AIDS e da defesa dos direitos de saúde sexual e reprodutiva.

A dificuldade de fixar o número de sexólogos em Portugal, associada à não regulamentação da profissão e à fluidez dos contornos da atividade, parece indicar que a sexologia constitui uma atividade profissional complementar a outras. Todavia, se atendermos à formação específica, à criação de uma clientela, e à existência de associações profissionais, somos levados a dizer que a sexologia é uma profissão em processo de emergência, à semelhança do que acontece noutros países $^{35}$.

Em Portugal, a sexologia foi fundada essencialmente por um grupo de médicos, psiquiatras na sua maioria, e a sua influência nos serviços públicos de saúde levou a uma crescente presença e proximidade de psicólogos. Este aspeto transparece nas diferenças de composição etária encontradas, em que os não médicos têm maioritariamente 25-39 anos e os médicos mais de 55 anos. $\mathrm{O}$ facto de os homens serem comparativamente mais velhos do que as mulheres reflete possivelmente o facto de culturalmente as mulheres terem estado afastadas das questões de sexualidade, especialmente no período anterior à restauração da democracia em Portugal, em 1974. A feminização dos sexólogos em Portugal, bem como a presença entre as mulheres de uma maioria de não médicas, segue a tendência europeia (exceto a França em que a feminização não se fez acompanhar de um processo de desmedicalização) ${ }^{8,36}$. Os dados do inquérito mostram que, à semelhança do Reino Unido ${ }^{37}$, o sexólogotipo português é do sexo feminino e não médico. Porém, a baixa taxa de resposta, nomeadamente dos membros da SPA, pode ter tido influência nestes resultados.

Tal como verificado em estudos anteriores ${ }^{38}$, a identificação com a designação de educador sexual é mais consensual do que o termo sexólogo, sendo este encarado como uma forma redutora de categorizar a atividade profissional desenvolvida, tendo por base essencialmente uma especialização adquirida e não englobando a totalidade dos aspetos incluídos nessa atividade. Por outro lado, a dedicação limitada à prática da sexologia também pode ser um fator explicativo, já apontado noutras pesquisas ${ }^{37}$. Mas foram essencialmente os sexólogos não médicos a referir conside- 
rar-se significativamente mais como educadores sexuais, enquanto os médicos foram quem mais indicou outra categoria (andrologista, por exemplo), para além da de sexólogo e terapeuta sexual, o que pode deixar antever que a sexologia é (ainda) uma atividade pouco prestigiante.

A construção da identidade social resulta, por um lado, da atribuição de identidade pelas instituições e atores em interação direta com o indivíduo que origina a identidade social "virtual”; e, por outro, da interiorização ativa pelo próprio indivíduo que dá origem à identidade social "real". Ambas as dimensões parecem estar em construção na identidade dos sexólogos, permanecendo em aberto a discussão dos critérios para a integração na profissão e para a sua autonomeação ${ }^{39}$. À semelhança de outros estudos, a problemática das relações de género parece sobrepor-se à questão da relação entre médicos e não médicos no campo e ao maior prestígio concedido aos primeiros $^{40}$, que são na sua maioria homens ${ }^{8}$.

Os vários profissionais que se dedicam atualmente à sexologia fazem-no com regularidades e especificidades distintas. Os diferentes tipos de sexólogos identificados no nosso estudo, os por vocação, pela prática clínica, por certificação, cientistas sociais e por mediatização, apresentam caraterísticas-tipo próximas dos grupos identificados numa recente investigação qualitativa realizada na Suécia através de entrevistas a membros da Sociedade Sueca de Sexologia. Nessa pesquisa, os tipos identificados foram os pioneiros, os sexólogos-competência, os empresários, os sexólogos de pesquisa e os não profissionais. A principal semelhança é entre os sexólogos por vocação e os aqui chamados pioneiros, tanto em termos da sua formação de base (médicos) como nas atividades desenvolvidas (criação de associações, formações e consultas clínicas), e ainda na forte dedicação à sexologia. Outro aspeto comum prende-se com a valorização pela generalidade dos sexólogos da realização de investigação em sexologia ${ }^{35}$.

$\mathrm{Na}$ nossa pesquisa verificou-se uma ligação importante entre o subgrupo pioneiro de psiquiatras dos sexólogos por vocação e alguns psicólogos clínicos, nomeadamente dos sexólogos por certificação. Foi esse subgrupo de psiquiatras quem lhes deu formação e os integrou nas suas consultas, e passou a desenvolver atividades em conjunto com eles, nomeadamente de terapia sexual, investigação e formação em questões de sexualidade. O elevado reconhecimento dos sexólogos por vocação não se deve somente ao facto de terem lançado as bases da sexologia, mas também ao de manterem um vasto trabalho de longos anos nas questões da sexualidade, quer em termos da sua prática clínica, quer na formação e no treino profissional, tendo ainda um papel de destaque na construção da sexologia em Portugal.

\section{Conclusão}

Este artigo analisou a pertinência social, real e simbólica da emergência da profissão de sexólogo em Portugal. Os dados sugerem que não existe uma profissionalização efetiva da sexologia, não havendo um monopólio legalmente organizado do exercício da atividade nem uma produção coletiva de normas, ainda que existam associações profissionais. Porém, vários praticantes se autodefinem como sexólogos, o que faz com que seja importante compreender as suas representações acerca da profissão, e a interpretação que fazem do seu trabalho e do trabalho desenvolvido por outros. 


\section{Colaboradores}

V Alarcão trabalhou na concepção e delineamento do estudo; na coleta, análise e interpretação dos dados; na redação e revisão crítica relevante do conteúdo intelectual do manuscrito. FL Machado e A Giami trabalharam na discussão e interpretação dos dados e na revisão crítica relevante do conteúdo intelectual do manuscrito.

\section{Agradecimentos}

Os autores gostariam de agradecer às três associações nacionais, Sociedade Portuguesa de Sexologia, Sociedade Portuguesa de Andrologia, Associação para o Planeamento da Família, por toda a colaboração na implementação deste projeto, ao Professor Doutor Nuno Monteiro Pereira pela ligação aos estudantes do Mestrado Transdisciplinar de Sexologia da Universidade Lusófona, e a todos os participantes deste estudo.

Por fim, os autores estão gratos a toda a equipa de investigação, nomeadamente ao Professor Doutor Alberto Galvão-Teles, e às entrevistadoras Ana Beato, Vera Forjaz e em especial Joana Almeida, a quem agradecemos também uma primeira revisão do artigo.

\section{Referências}

1. Giami A. The social and professional diversity of sexology and sex-therapy in Europe. In: Hall K, Graham C, editors. Cultural Context of Sexual Pleasure and Problems: Psychotherapy with Diverse Clients. London: Routledge; 2012. p. 375-393.

2. Foucault M. História da Sexualidade I - A Vontade de Saber. Lisboa: Relógio d' Água; 1994.

3. Béjin A. Crepúsculo dos psicanalistas, manhã dos sexólogos. In: Ariès P, Béjin A, organizadores. Sexualidades ocidentais. São Paulo: Brasiliense; 1987. p. 210-235.

4. Béjin A. O poder dos sexólogos e a democracia sexual. In: Ariès P, Béjin A, organizadores. Sexualidades ocidentais. São Paulo: Brasiliense; 1987. p. 236-254.

5. Irvine JM. Disorders of Desire: Sexuality and Gender in Modern American Sexology. Philadelphia: Temple University Press; 2005.

6. Weeks J. Sexuality and Its Discontents: Meanings, Myths, and Modern Sexualities. London: Taylor \& Francis; 2002.

7. Russo J. A terceira onda sexológica: Medicina Sexual e farmacologização da sexualidade. Sex., Salud Soc. 2013; 14:172-194.

8. Giami A, Colomby Pd. La profession de sexologue en Europe: diversité et perspectives communes. Sexologies 2006; 15(1):7-13.

9. Giami A, Colomby P. Sexology as a profession in France. Archives of Sexual Behavior 2003; 32(4):371-379.

10. Dupras A. La professionnalisation de la sexologie au Québec. Sexologies 2006; 15(1):58-63.

11. Giami A, Russo J. The Diversity of Sexologies in Latin America: Emergence, Development, and Diversification. International Journal of Sexual Health 2013; 25(1):1-12.

12. Bancroft J. A history of sexual medicine in the United kingdom. J Sex Med 2005; 2(4):569-574.

13. Bonierbale M, Waynberg J. 70 ans sexologie française. Sexologies 2007; 16(3):238-258.

14. Lewis R, Wagner G. History of the International Society of Sexual Medicine (ISSM) - The Beginnings. J Sex Med 2008; 5(3):740-745.

15. Cavalcanti R. Alguns aspectos da história da sexologia no Brasil. Rev Brasileira de Sexualidade Humana 1992;3(1):56-65.

16. Rodrigues ML. Sociologia das Profissões. Oeiras: Celta; 1997.

17. Carapinheiro G, Rodrigues ML. Profissões: protagonismos e estratégias. In: Costa AF, Viegas JML. Portugal, que Modernidade? Oeiras: Celta; 1998. p. 147-164.

18. Delicado A, Borges V, Dix S. Profissão e vocação: ensaios sobre grupos profissionais. Lisboa: Imprensa de Ciências Sociais; 2010.

19. Freidson E. Professional Powers: A Study of the Institutionalization of Formal Knowledge. Chicago: University of Chicago Press; 1988.

20. Policarpo V. Sexualidades em construção: entre o público e o privado. In: Nunes de Almeida A, organizador. História da vida privada em Portugal. Lisboa: Círculo de Leitores; 2011. p. 48-79.

21. Albuquerque A. O Hospital Júlio de Matos tem consulta de Sexologia há 34 anos. Congress: Sexology past, present and future: Celebrating a century of the multidisciplinary science of sex European Federation of Sexology Congress, Oporto, 9th-13th May 2010. 
22. Moreira A. Aspectos Históricos da Andrologia. Andrologia Clínica. 2000:27-40.

23. Vaz JM. Sexualidade e história. In: Fonseca L, Soares C, Vaz JC. A sexologia: perspectiva multidisciplinar II. Coimbra: Quarteto Editora; 2003. p. 17-42.

24. Kontula O. An Essential Component in Promoting Sexual Health in Europe is Training in Sexology. International Journal of Sexual Health 2011; 23(3):168-180.

25. Figueiredo CC. Redes sociais e politicas: genealogia das políticas públicas de Educação Sexual. Lisboa: Universidade de Lisboa; 2011.

26. Vilar D. Falar Disso. A Educação Sexual nas Famílias dos Adolescentes. Porto: Edições Afrontamento; 2002.

27. Lucas JS. Mudanças em percepções e atitudes favoráveis à prevenção da SIDA. Revista Portuguesa de Saúde Pública 1990; 8(4):61-64.

28. Lucas JS. Os portugueses e a SIDA: inquérito nacional sobre conhecimentos, atitudes e comportamentos associados com a SIDA. Revista Portuguesa de Saúde Pública 1987; 5(3/4):98-100.

29. Amaro F, Dantas AM, Cunha Teles L. Sexual behaviour in the city of Lisbon. International Journal of STD \& AIDS 1995; 6(1):35-41.

30. Amaro F, Frazao C, Pereira ME, Cunha Teles L. HIV/ AIDS risk perception, attitudes and sexual behaviour in Portugal. International Journal of STD \& AIDS. 2004; 15(1):56-60.

31. Ferreira PM, Cabral MV. Sexualidades em Portugal: comportamentos e riscos. Lisboa: Bizâncio; 2010.

32. Bajos N, Bozon M, Ferrand A, Giami A, Spira A. La Sexualité au temps du sida. Paris: Presses Universitaires de France; 1998.

33. Laumann EO, Gagnon JH, Michaels S, Michael RT, Coleman JS. Monitoring the AIDS epidemic in the United States: a network approach. Science 1989; 244(4909):1186-1189.
34. ACSF investigators. AIDS and sexual behaviour in France. Nature 1992; 360(6403):407-409.

35. Löfgren-Mårtenson L. From Pioneers to Professionals A qualitative study of sexologists in Sweden. Sexologies, European Journal of Sexology and Sexual Health 2015; 24(2):e37-e40.

36. Giami A, Chevret-Méasson M, Bonierbale M. Les professionnels de la sexologie en France: quelques évolutions. Premiers résultats de l'enquête nationale. Sexologies, European Journal of Sexology and Sexual Health 2009; 18(4):265-269.

37. Wylie KR, De Colomby P, Giami AJ. Sexology as a profession in the United Kingdom. International Journal of Clinical Practice 2004; 58(8):764-768.

38. Zamboni B. Identity, Training, and Expertise Among Sexual Health Professionals. International Journal of Sexual Health 2009; 21(2):132-144.

39. Dubar C, Tripier P. Sociologie des professions. Paris: Armand Colin; 1998

40. Freidson E. Profession of Medicine: A Study of the Sociology of Applied Knowledge. Chicago: University of Chicago Press; 1988.

Artigo apresentado em 27/03/2015

Aprovado em 03/07/2015

Versão final apresentada em 05/07/2015 